\title{
Molecular analysis of a flagellar core protein gene of Serpulina (Treponema) hyodysenteriae
}

\author{
Marcel B. H. Koopman, Ellen BaAts, Olav S. de Leeuw, Bernard A. M. van der Zeiust \\ and JOHANNES G. KuSTERS* \\ Department of Bacteriology, Institute of Infectious Diseases and Immunology, School of Veterinary Medicine, \\ University of Utrecht, PO Box 80.165, 3508 TD Utrecht, The Netherlands
}

(Received 5 October 1992; revised 2 March 1993; accepted 9 March 1993)

\begin{abstract}
The flaB2 gene encoding a protein located in the core of the periplasmic flagella of Serpulina hyodysenteriae was cloned and sequenced. The FlaB2 protein consists of 285 amino acids and has a calculated molecular mass of $31 \cdot 1 \mathrm{kDa}$. Southern blot analysis indicated that at least one, and possibly two genes related to flaB2 are present in the genome of $S$. hyodysenteriae. Comparison of the amino acid sequence of FlaB2 to sequences present in data banks showed significant similarity with the core flagellins of other spirochaetes, in particular with a FlaB2 protein from Treponema phagedenis.
\end{abstract}

\section{Introduction}

The spirochaete Serpulina hyodysenteriae (formerly Treponema hyodysenteriae) is the aetiological agent of swine dysentery (Harris et al., 1972; Taylor \& Alexander, 1971). It is a spiral-shaped bacterium that preferentially colonizes the mucus gel covering the epithelium and the mucus-filled crypts of Lieberkühn in dysenteric pigs (Kennedy et al., 1988). To remain in the colon the bacteria must withstand the flow of the intestinal contents. There is no evidence that specific adhesion mechanisms are used for this in vivo, although in vitro $S$. hyodysenteriae adheres to epithelial cells (Knoop et al., 1979; Bowden et al., 1989). Most bacteria are immobilized in the viscous intestinal mucus but $S$. hyodysenteriae is highly motile in this environment (Kennedy et al., 1988). This association with the mucus may be the predominant mechanism of mucosal colonization used by $S$. hyodysenteriae (Kennedy et al., 1988 ) and hence motility may contribute to virulence of this organism.

The characteristic corkscrew-like movement by which $S$. hyodysenteriae and other spirochaetes propel themselves through viscous solutions is mediated by flagella that are located in the periplasmic space, completely

*Author for correspondence. Tel. 3130 534987; fax 3130540784.

The nucleotide sequence data reported in this paper have been submitted to GenBank and have been assigned the accession number X63513. surrounded by the outer membrane of the cell (CanaleParola, 1978; Paster \& Canale-Parola, 1980). S. hyodysenteriae has two bundles of seven to nine periplasmic flagella that are each attached subterminally to one cell end and overlap in the middle of the cell cylinder (Harris et al., 1972). Whereas most bacterial flagella have only one major flagellar protein, the periplasmic flagella of $S$. hyodysenteriae are complex and contain multiple major proteins. They consist of a core composed of three proteins (molecular masses 37,34 and $32 \mathrm{kDa}$, designated FlaB1, FlaB2 and FlaB3, respectively) and a sheath containing a $44 \mathrm{kDa}$ (FlaA1) and $35 \mathrm{kDa}$ (FlaA2) protein (Koopman et al., 1992a). With the exception of Borrelia burgdorferi (Coleman \& Benach, 1989) and Treponema zuelzera (Bharier \& Rittenberg, 1971), whose periplasmic flagella contain a single protein species, other spirochaetes have a similar flagella composition (Brahamsha \& Greenberg, 1988; Canale-Parola, 1978; Charon et al., 1992; Cockayne et al., 1987; Kelson et al., 1988; Nauman et al., 1969; Norris et al., 1988). In this paper we report the cloning and sequencing of a gene, flaB2, encoding the $34 \mathrm{kDa}$ flagellar core protein of $S$. hyodysenteriae and provide evidence that at least one, and possibly two, genes related to $f a B 2$ are present in the genome of $S$. hyodysenteriae.

\section{Methods}

Bacterial strains, culture conditions and cloning vectors. $S$. hyodysenteriae strain $\mathrm{C} 5$ is a haemolytic Dutch field isolate, isolated from the colon of a pig severely affected by swine dysentery. Escherichia 
coli Y1090 (Young \& Davis, 1983) was used for library was used for library construction and screening; E. coli DH5 $\alpha \mathrm{F}^{\prime}$ (Bethesda Research Laboratories Life Technologies) was used in subcloning experiments. $S$. hyodysenteriae was cultured as described previously (Koopman $e t$ al., 1992b). E. coli was grown in LB broth or on LB agar plates (Sambrook et al., 1989). Phage R408 and phage $\lambda$ ZAP were obtained from Stratagene,

DNA cloning techniques and screening of the genomic library. Unless stated otherwise, standard cloning procedures were used for all DNA manipulations (Sambrook et al., 1989). Plasmid pBluescript II $\mathrm{KS}^{+}$ (Stratagene) was used in subcloning experiments. A genomic DNA library was constructed in phage $\lambda$ ZAP (Stratagene) as described by Koopman et al. (1992b). Phagemid pBluescript SK(-) were excised with helper phage from $\lambda Z A$ AP phages according to the manufacturer's instruction (Stratagene), eliminating the need to subclone DNA inserts from the $\lambda Z A P$ phage into a plasmid by restriction digestion and ligation. To screen the genomic library with a radiolabelled probe, nitrocellulose filter lifts were prepared.

DNA fragments to be used in Southern blotting experiments and screening of the library were isolated with Gene Clean (Bio101) and labelled with $\left[\alpha-{ }^{32}\right.$ P]dATP (Amersham) using a random-primed labelling kit (Boehringer Mannheim). Oligonucleotides (Pharmacia) were 5 -end-labelled using T4 polynucleotide kinase and $\left[\gamma^{-32} \mathrm{P}\right] \mathrm{ATP}$ (Amersham).

For Southern blotting, DNA fragments were separated on agarose gels, transferred to Hybond-N nylon filters (Amersham) and fixed by exposure to UV. Filters were prehybridized, essentially as described by Sambrook et al. (1989), for $6 \mathrm{~h}$ at $45^{\circ} \mathrm{C}$ in $6 \times$ SSPE, $5 \times$ Denhardt's reagent, $0.5 \%$ SDS and $100 \mu \mathrm{g}$ heat-denatured salmon sperm DNA $\mathrm{ml}^{-1}$. Radiolabelled probe was added, and hybridization was performed at $45^{\circ} \mathrm{C}$ for $16 \mathrm{~h}$. Blots were washed in $6 \times$ SSPE, $0.1 \%$ SDS at $45^{\circ} \mathrm{C}$ (non-stringent) or at higher stringency $(0.5 \times$ SSPE, $0.1 \%$ SDS at $60^{\circ} \mathrm{C}$ ). Autoradiography of blots was done with intensifying screens at $-70^{\circ} \mathrm{C}$, using Fuji XR film.

Double-stranded DNA sequencing was performed on both strands with the $\mathrm{T} 7$ sequencing kit from Pharmacia according to the manufacturer's description, using the T3 and T7 primer and oligonucleotides derived in the course of sequencing.

Polymerase chain reaction (PCR) amplification of core flagellar sequences was performed with two oligonucleotide mixtures as PCR primers. One oligonucleotide mixture was derived from the $\mathrm{N}$-terminal amino acid sequence of the core proteins of $S$. hyodysenteriae (Koopman et al., 1992a) (MIINNNI: 5' GGGGAATTCATGAT(T/C/A)AT(T/C/A)AA(T/C)AA(T/C)AA(T/C)AT 3'). The second oligonucleotide mixture was deduced from a conserved amino acid sequence close to the carboxy-terminal end of flagellar proteins of a number of bacteria (see Results and Discussion) (MLAQANQ: $5^{\prime}$ GGGGAATTCTG(A/G)TT(A/T/G/C)GC(T/C)TG(A/T/G/C)$\left.\mathrm{GC}(\mathrm{A} / \mathrm{T} / \mathrm{G} / \mathrm{C}) \mathrm{A}(\mathrm{G} / \mathrm{A}) \mathrm{CAT} 3^{\prime}\right)$. A recognition site for $E c o$ RI was added to the $5^{\prime}$ end of the oligonucleotides to facilitate subcloning of the amplified DNA in EcoRI-digested pBluescript II $\mathrm{KS}^{+}$. Cycle parameters were: $1 \mathrm{~min}$ at $95^{\circ} \mathrm{C}, 1 \mathrm{~min}$ at $35^{\circ} \mathrm{C}$ and $2 \mathrm{~min}$ at $72^{\circ} \mathrm{C}$. For analysis of the amplification products, a $10 \mu l$ aliquot of the reaction mixture was subjected to electrophoresis on a $1.5 \%$ agarose gel. Amplified bands were visualized by ethidium bromide staining.

Computer analysis of DNA sequences. Nucleotide sequences were analysed with the $\mathrm{PC} / \mathrm{Gene}$ computing programs (release 6.50; Genofit). The FASTA program, release 1.3 (Pearson \& Lipman, 1988) was used to compare nucleotide and amino acid sequences with the following data bases: EMBL (release 27.0), GenBank (release 67.0), NBRF/PIR (release 28.0), Swiss-Prot (release 18.0) and Brookhaven (release 4.0). Homologous sequences were aligned with the CLUSTAL computer program (Higgins \& Sharp, 1988, 1989), using the default values.

\section{Results and Discussion}

\section{Design of oligonucleotide mixtures to PCR amplify flagellar core sequences}

A number of studies have shown that the termini of flagellins display strong conservation whereas the middle part is variable (Joys, 1985; Martin \& Savage, 1988; Nuijten et al., 1990). To obtain a DNA probe for a flagellar core gene of $S$. hyodysenteriae we compared the amino acid sequences of core flagellar proteins of spirochaetes (Champion et al., 1990; Gassmann et al., 1989; Mitchison et al., 1991; Pallesen \& Hinderson, 1989 ) with the amino acid sequences of a number of other flagellar proteins present in databases (Guerry et

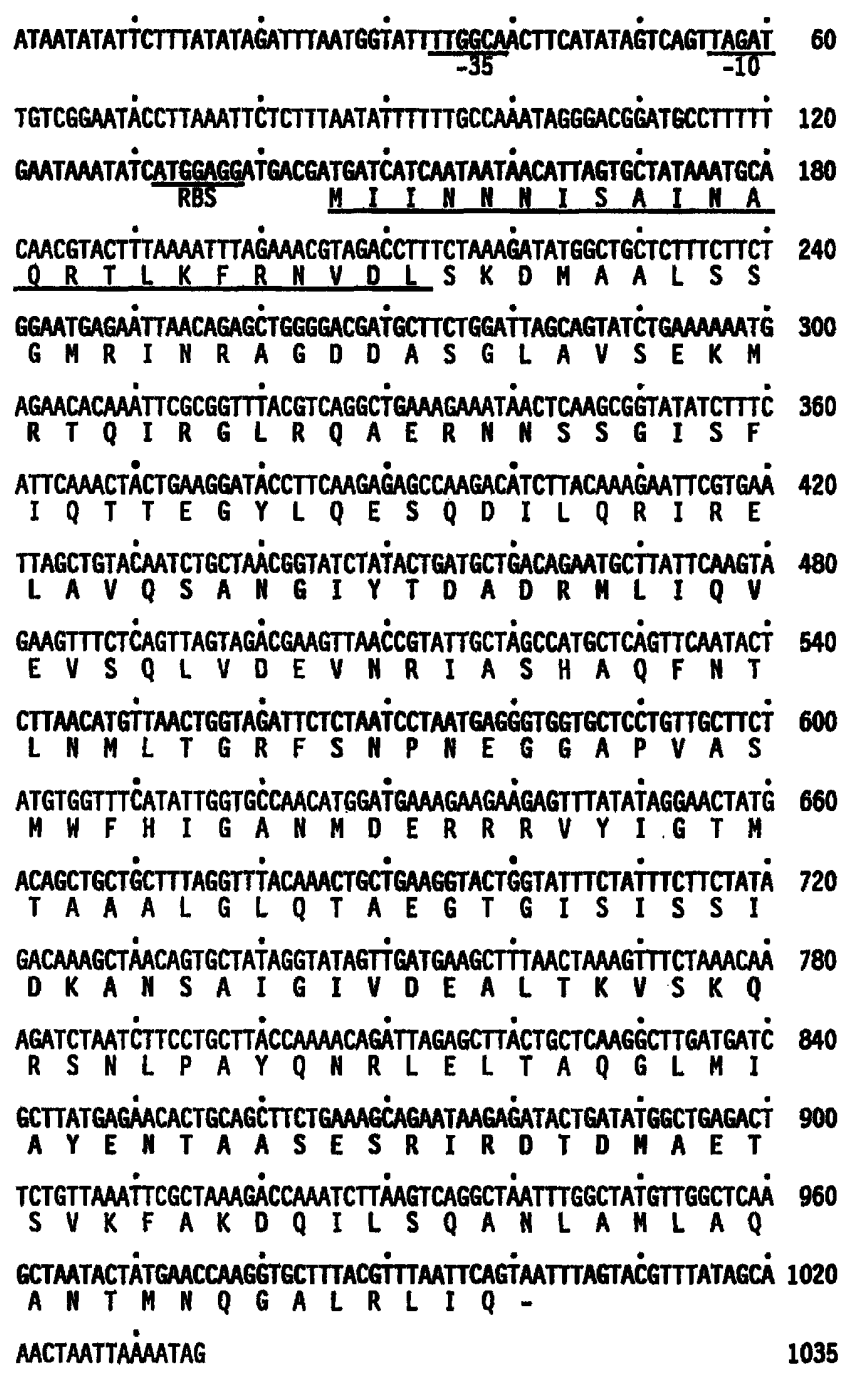

Fig. 1. Nucleotide sequence and deduced amino acid sequence of the $S$. hyodysenteriae core flagellar gene $f a B 2$. Amino acid residues that are in agreement with the $\mathrm{N}$-terminal sequence of native flagellar protein are underlined. The putative ribosome-binding site (RBS) and sequences that show similarity to the $E$. coli consensus -10 and -35 sequences are also underlined. 

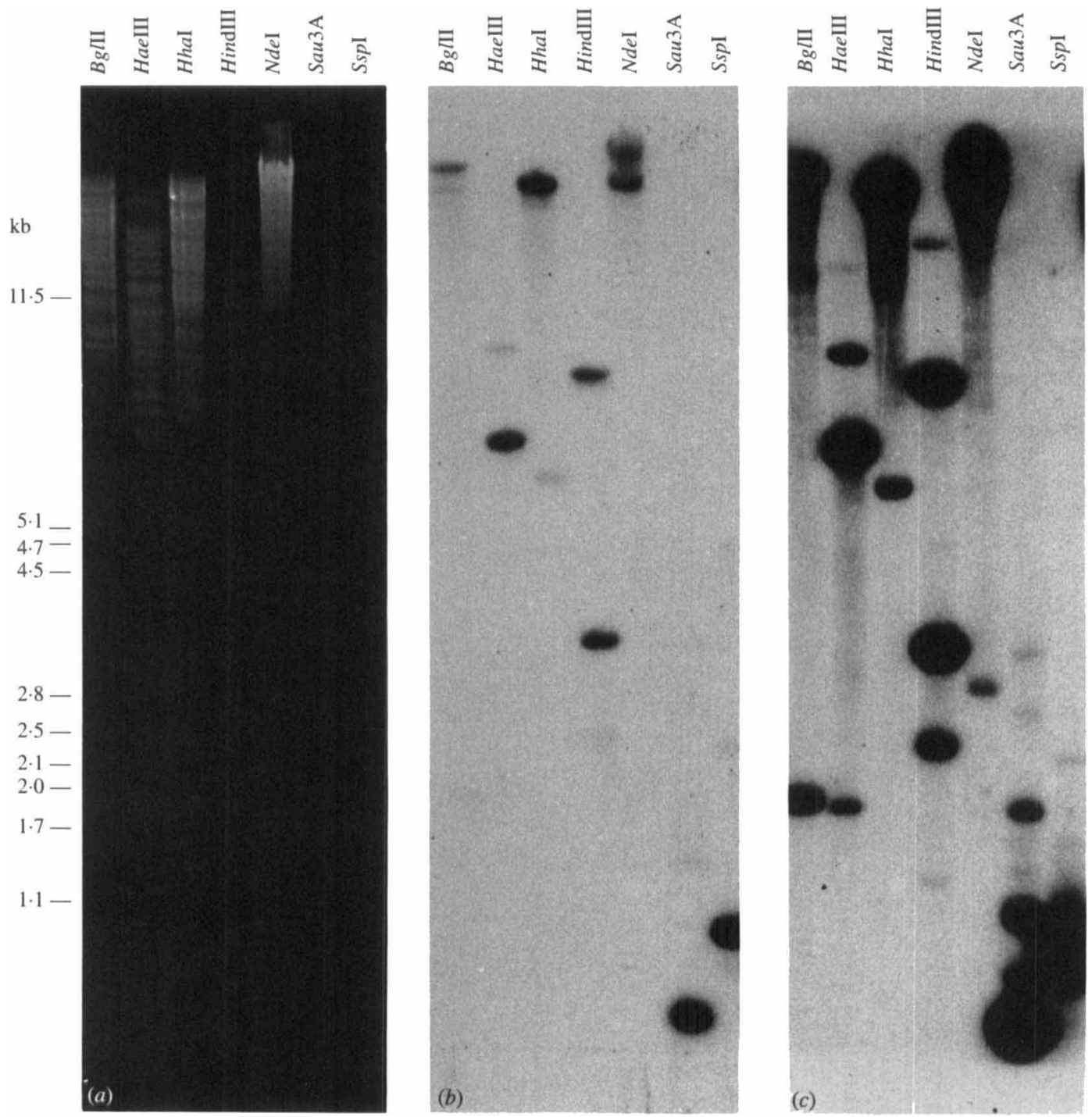

Fig. 2. Hybridization of the $f a B 2$ gene with chromosomal DNA of $S$. hyodysenteriae C5. Chromosomal DNA fragments obtained after digestion with various restriction endonucleases were separated in a $0.6 \%$ agarose gel, blotted onto nitrocellulose and hybridized with a PCR-amplified $f a B 2$ sequence. Size markers are indicated on the left. (a) Ethidium-bromide-stained agarose gel; $(b)$ autoradiograph after stringent washing of the Southern blot; $(c)$ autoradiograph after low-stringency washing of the Southern blot.

al., 1990; Harshey et al., 1989; Joys, 1985; Kuwajima et al., 1986; Lavallie \& Stahl, 1989; Martin \& Savage, 1988; Nuijten et al., 1990; Totten \& Lory, 1990). This revealed the presence of an amino acid sequence (MLAQANQ) that is not only present at the carboxyterminal end of most spirochaete core flagellar proteins but also at the carboxy-terminal ends of other flagellar proteins of remotely related bacteria. We expected that a highly similar amino acid sequence would be present at the carboxyl-terminal end of core flagellar proteins of $S$. hyodysenteriae. Thus, a mixture of oligodeoxynucleotides covering all possible sequences coding for the amino acid sequence MLAQANQ was used in conjunction with mixed oligonucleotides derived from the known $\mathrm{N}$ terminus (MINNNI) of the $S$. hyodysenteriae core proteins (Koopman et al., 1992a) to amplify core flagellar gene sequences from the chromosome of $S$. hyodysenteriae by PCR. This resulted in a PCR product of approximately $800 \mathrm{bp}$, corresponding to the size of the expected PCR products of other spirochaetes. Partial sequencing of the amplified DNA fragment confirmed that it encoded part of a flagellar core gene (data not shown).

\section{Cloning of the flaB2 gene}

The radiolabelled PCR product was used to screen an $S$. hyodysenteriae genomic library. This screening was designed to obtain clones containing an entire core flagellar gene and to correct PCR errors. Approximately 
50000 plaques were screened. Twenty-eight of these reacted positively with the probe. The insert DNA of these clones was isolated and restricted with EcoRI and HindIII. Agarose gel electrophoresis of the DNAs revealed four different, but related, restriction patterns (results not shown). Some of the restriction fragments were common to all clones, indicating that the clones contain DNA from the same area of the $S$. hyodysenteriae chromosome. The smallest of the 28 plasmids (designated pC1) containing $2 \mathrm{~kb}$ of insert DNA was chosen for nucleotide sequence analysis.

Nucleotide sequence and deduced amino acid sequence of the flaB2 gene

The nucleotide sequence of part of the $S$. hyodysenteriae insert DNA in pC1 was determined. The sequence data in Fig. 1 show an 855 bp open reading frame, corresponding to 285 amino acid residues. The first 23 amino acid residues are in agreement with the previously determined $\mathrm{N}$-terminal amino acid sequence of the $34 \mathrm{kDa}$ core flagellin of $S$. hyodysenteriae (Koopman et $a l ., 1992 a$ ). Since this is the second-largest core flagellin the gene is designated $f a B 2$ and the protein it encodes is called FlaB2. The calculated molecular mass of FlaB2 is $31.1 \mathrm{kDa}$, which is slightly less than the apparent molecular mass of the native protein on SDS-PAGE gels. This discrepancy may be the result of aberrant migration of the protein on SDS-PAGE gels. Alternatively, the native FlaB2 core protein may be post-translationally modified, as has been described for flagellar proteins from a number of bacteria (Joys \& Kim, 1979; Logan et al., 1989; Wieland et al., 1985). The G+C percentage of $f a B 2$ is $36 \mathrm{~mol} \%$, which is higher than the reported $28 \mathrm{~mol} \% \mathrm{G}+\mathrm{C}$ content of the $S$. hyodysenteriae genome (Coene et al., 1989). As in flagellins of other bacteria, there are no cysteine residues present. A consensus $E$. coli Shine-Dalgarno sequence is present upstream from the initiation codon. Although sequences that show some similarity to $E$. coli -10 or -35 promoter consensus sequences can be discerned, $E$. coli transformed with plasmid $\mathrm{pC} 1$ did not produce amounts of flagellin that could be detected on immunoblots with specific antibodies (results not shown). Perhaps the $f a B 2$ gene forms part of an operon. Alteratively, it may be transcribed from an unusual promoter that is not recognized by $E$. coli. In many bacteria the expression of flagellar genes and chemotaxis and motility genes is regulated by a $\sigma$ factor that resembles the $B$. subtilis $\sigma^{28}$ factor (Helmann, 1991). A $\sigma^{28}$-like promoter sequence has also been identified upstream of the $f l a B$ flagellar genes of $T$. pallidum (Champion et al., 1990; Pallesen \& Hindersson, 1989). However, a $\sigma^{28}$ recognition sequence can not be discerned with the flaB2 gene of $S$. hyodysenteriae.
Probing S. hyodysenteriae DNA with the flaB2 gene

The N-terminal amino acid sequences of the three core proteins of $S$. hyodysenteriae are highly similar, but not identical (Koopman et al., 1992a), suggesting that the core proteins are encoded by separate genes. DNA hybridization studies were therefore performed to determine whether genes related to $f a B 2$ are present in the $S$. hyodysenteriae chromosome. Chromosomal DNA was restricted with three endonucleases that do not cut in the $f a B 2$ gene (BglII, HaeII, HhaI, or $S s p \mathrm{I}$ ), or restricted with $H$ indIII, for which one site is present. The DNA was then blotted to nitrocellulose and hybridized to a radiolabelled PCR fragment representing the entire $f l a B 2$ gene. After high-stringency washing of the blot the probe hybridized to a single band in BglII, HaeIII, HhaI or SspI-cut DNA and to two bands in chromosomal DNA cut with HindIII (Fig. $2 b$ ). The hybridizing HaeIII and $H h a \mathrm{I}$ bands are large enough to accommodate more than one $f l a B 2$ gene, but the single SspI fragment (approximately $1 \mathrm{~kb}$ ) that hybridizes to the $f a B 2$ probe is not. These results show that there is a single $f a B 2$ gene in the $S$. hyodysenteriae chromosome. When blots were washed under conditions of lower stringency, additional bands were observed (Fig. $2 c$ ). These extra bands may represent $f l a B$ genes. The extra bands observed in the lane containing chromosomal DNA cut with SspI indicate that a second $f a B$ gene resides completely or for the most part on the $800 \mathrm{bp}$ fragment and perhaps partly on the fragment represented by the faint $2 \cdot 2 \mathrm{kbp}$ band. Alternatively, the latter band may contain (part of) a third $f l a B$ gene. In any case, the third $f a B$ gene that should be present on the chromosome of $S$. hyodysenteriae will be weakly related to the other two $f a B$ genes. A similar situation exists in T. pallidum (Champion et al., 1990; Pallesen \& Hindersson, 1989).

\section{Homology analysis of FlaB2 with other flagellins}

The deduced amino acid sequence of the $S$. hyodysenteriae $\mathrm{FlaB} 2$ protein was aligned with other spirochaete class B proteins cloned and sequenced so far. Significant homology was observed (Fig. 3). This alignment reveals an amino acid identity of $61.2 \%$, $59.8 \%$ and $59.3 \%$, respectively, with the FlaB1, the FlaB2 and the FlaB3 flagellar core proteins of Treponema pallidum (Champion et al., 1990; Pallesen \& Hinderson, 1989). The $S$. hyodysenteriae FlaB2 protein also showed $58.5 \%$ identity with the recently cloned FlaB2 protein of Leptospira borgpetersenii (Mitchison et al., 1991), 62.9\% identity with the FlaB2 of Treponema phagedenis (Limberger et al., 1992) and (although not a 'true' core protein) $39.3 \%$ identity with the flagellin protein of Borrelia burgdorferi (Gassmann et al., 1989). The $S$. hyodysenteriae FlaB2 protein and other spirochaete 


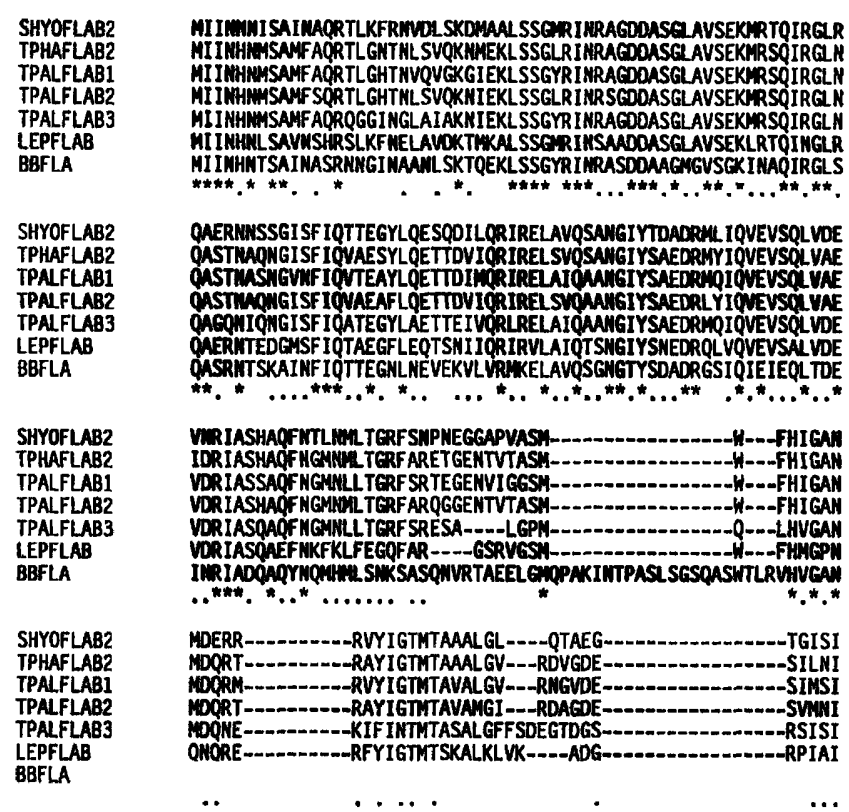

SHYOFLAB2 SSIOKANSAIGIVOEALTKUSKORSMLPAYQWRLEL TAQGLMIAYETTAASESRIRDTD TPHAFLAB2 TPALFIAB] TPALFLAB1 TPALFLAB2 TPALFLAB3 LEPFLAB
BBFLA

SHYOFLAB2 TPHAFLAB2 TPALFLABI TPALFLAB2 TPALFLAB3 BBFLA

MAAESRIRDVDH

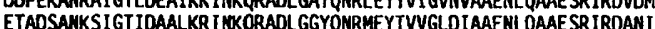
DSPEKAYRAIGTL OAIKR IKK DTDOCARA G SSPGEANDVIGLADAALTRIMKGRADMGAYYMRLEYTAKGLMGAYEMMASESRIRDADY TTTVDANTSLAKIEMAIRHI SDQRAIL GAFQWRLESIKDSTEYAIEMLKASYAQIKDATH

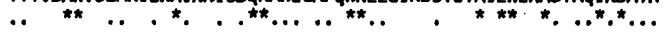

AETSVKFAKDQIL SQANLAMLAQANTMNQGALRLIQ--

AKENOYTKWOILVOSGTALLAOANOATOSVLSLLR-

NCWNEYTKOYR TOSGTA LAOANTSAOSILSILR-

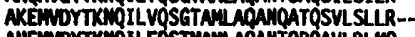

AHEWOYTKMQILEOSTHAWLAANTQPQAVLRLMQ--

TOEVYATTMSILTOSAMAMIAQANOVPOMMLSLLR-

Fig. 3. Comparison of the core flagellin FlaB2 (SHYOFLAB2) to the flagellin of $L$. borgpetersenii (LEPFLAB), the $T$. phagedenis FlaB2 core flagellin (TPHAFLAB2), the three core flagellins of $T$. pallidum (TPALFLAB1-3) and the flagellin of $B$. burgdorferi (BBFLA). Identical amino acids are indicated with an asterisk, conserved substitutions by single dots. Spaces (dashes) are included to obtain maximum alignment.

flagellar core proteins share several characteristics with flagellins from a wide range of bacteria: the amino- and carboxyl-terminal regions of the proteins are conserved and they do not have a consensus signal sequence at their amino-terminus. Hence, spirochaete core flagellar proteins may be secreted through the centre of the flagellar filament to polymerize at its tip, a mechanism similar to that suggested in E. coli and Salmonella typhimurium. The terminal regions of the flagellins have an important role in this transport and assembly (Homma et al., 1987; Kuwajima, 1988; Kuwajima et al., 1989; Lavallie \& Stahl, 1989).

All three core flagellar genes of $T$. pallidum have been sequenced. When comparing the $S$. hyodysenteriae FlaB2 protein with these three proteins, the highest degree of homology is not with the $T$. pallidum FlaB2 protein but with the FlaB1 protein. Since the differences in homology between FlaB1 and FlaB2 are very small, this finding does not necessarily imply that $S$. hyodysenteriae FlaB2 is phylogenetically most closely related to the $T$. pallidum FlaB1. It is more probably a reflection of the strong conservation of functional domains of the spirochaetal flagellar core proteins. The latter is substantiated by the finding that all core proteins show approximately $60 \%$ identity with the $S$. hyodysenteriae FlaB2. Because this conservation is probably imposed by functional and structural demands on the core proteins we feel that, until we known more about the functional relationship of the three different spirochaetal flagellar core proteins, phylogenetic relationships based on these proteins are merely speculative. The phylogenetic relationships as calculated from the DNA sequence alignment of the Fla genes (not shown) are well in line with those for the rRNA sequences as reported by Stanton et al. (1991). Further studies are required to find out what the function of the periplasmic flagella of $S$. hyodysenteriae is and why $S$. hyodysenteriae and most other spirochaetes have multiple flagellar proteins.

This study was supported by Solvay Duphar BV Weesp, The Netherlands. We gratefully acknowledge the use of the services and facilities of the Dutch national NWO/SURF Expertise Center CAOS/CAMM, under grant numbers SON 326-052 and STW NCH99.1751. We thank C. Buskens for experimental assistance.

Bharier, M. A. \& Rittenberg, S. C. (1971). Chemistry of axial filaments of Treponema zuelzerae. Journal of Bacteriology 105, 422.429.

Bowden, C. A., Joens, L. A. \& Kelly, L. M. (1989). Characterization of the attachment of Treponema hyodysenteriae to Henle intestinal epithelial cells in vitro. American Journal of Veterinary Research 50,

Brahamsha, B. \& Greenberg, E. P. (1988). A biochemical and cytological analysis of the complex periplasmic flagella from Spirochaeta aurantia. Journal of Bacteriology 170, 4023-4032.

Canale-Parola, E. (1978). Motility and chemotaxis of spirochetes. Annual Review of Microbiology 32, 69-99.

Champion, C. I., Miller, J. N., Lovett, M. A. \& Blanco, D. R. (1990). Cloning, sequencing, and expression of two class B endoflagellar genes of Treponema pallidum subsp. pallidum encoding the 34.5- and 31.0-kilodalton proteins. Infection and Immunity 58,

Charon, N. W., Greenberg, E. P., Koopman, M. B. H. \& Limberger, R. J. (1992). Spirochete chemotaxis, motility, and the structure of the spirochetal periplasmic flagella. Research in Microbiology 143,

Cockayne, A., Bailey, M. J. \& Penn, C. W. (1987). Analysis of sheath and core structures of the axial filament of Treponema pallidum. Journal of General Microbiology 113, 1397-1407.

Coene, M., Agliano, M., Paques, A. T., Cattani, P., Dettori, G., SanNa, A. \& Cocito, C. (1989). Comparative analysis of the genomes of intestinal spirochetes of human and animal origin. Infection and Immunity 57, 138-145.

Coleman, J. L. \& BenaCH, J. L. (1989). Identification and characterization of an endoflagellar antigen of Borrelia burgdorferi. Journal of Clinical Investigation 84, 322-330.

Gassmann, G. S., Kramer, M., Goebel, U. B. \& Wallich, R. (1989). Nucleotide sequence of a gene encoding the Borrelia burgdorferi flagellin. Nucleic Acids Research 17, 3590. 
Genomic organization and expression of Campylobacter flagellin genes. Journal of Bacteriology 172, 1853-1860.

Harris, D. L., Glock, R. D., Christensen, C. R. \& Kinyon, J. M. (1972). Swine dysentery: inoculation of pigs with Treponema hyodysenteriae (new species) and reproduction of the disease. Veterinary Medicine and Small Animal Clinician 67, 61-64.

Harshey, R. M., Estepa, G. \& Yanagi, H. (1989). Cloning and nucleotide sequence of a flagellin-coding gene (hag) from Serratia marcescens 274. Gene 79, 1-8.

HelmanN, J. D. (1991). Alternative sigma factors and the regulation of flagellar gene expression. Molecular Microbiology 5, 2875-2882.

Higgins, D. G. \& ShaRP, P. M. (1988). Clustal: a package for performing multiple alignment on a microcomputer. Gene 73, 237-244.

HigGins, D. G. \& Sharp, P. M. (1989). Fast and sensitive multiple sequence alignments on a microcomputer. CABIOS Communication 5, 151-153.

Homma, M., Fujita, H., Yamaguchi, S. \& InNo, T. (1987). Regions of Salmonella typhimurium flagellin essential for its polymerization and excretion. Journal of Bacteriology 169, 291-296.

JoYs, T. M. (1985). The covalent structure of the phase-1 flagellar filament protein of Salmonella typhimurium and its comparison with other flagellins. Journal of Biological Chemistry 60, 15758-15761.

Joys, T. M. \& KIM, H. (1979). Identification of $N$-methyl-lysine residues in the phase-1 flagellar protein of Salmonella typhimurium. Microbios Letters 7, 65-68.

Kelson, J. S., Adler, B., Chapman, A. J. \& Faine, S. (1988). Identification of leptospiral flagellar antigens by gel electrophoresis and immunoblotting. Journal of Medical Microbiology 26, 47-53.

KENNEDY, M. J., ROSNICK, D. K., ULRICH, R. G. \& YANCEY, R. J., JR (1988). Association of Treponema hyodysenteriae with porcine intestinal mucosa. Journal of General Microbiology 134, 1565-1576.

KnOOP, F. C., Schrank, G. D. \& Ferraro, F. M. (1979). In vitro attachment of Treponema hyodysenteriae to mammalian epithelial cells. Canadian Journal of Microbiology 25, 399-405.

Koopman, M. B. H., BaAts, E., van Vorstenbosch, C. J. A. H. V., VAN DER ZEIJST, B. A. M. \& Kusters, J. G. (1992a). The periplasmic flagella of Serpulina (Treponema) hyodysenteriae are composed of two sheath proteins and three core proteins. Journal of General Microbiology 138, 2697-2706.

Koopman, M. B. H., de Leeuw, O. S., van der ZeiJst, B. A. M. \& KUSTERS, J. G. (1992b). Cloning and DNA sequence analysis of a Serpulina (Treponema) hyodysenteriae gene encoding a periplasmic flagellar sheath protein. Infection and Immunity 60, 2920-2925.

KuWAJMA, G. (1988). Construction of a minimum-size functional flagellin of Escherichia coli. Journal of Bacteriology 170, 3305-3309.

Kuwajima, G., Asaka, J.-I., Fujiwara, T., Fujiwara, T., Node, K. \& KonDO, E. (1986). Nucleotide sequence of the hag gene encoding flagellin of Escherichia coli. Journal of Bacteriology 168, 1479-1483.

Kuwajima, G., KaWAGish, I., Homma, M., AsaKa, J.-I., Kondo, E. \& MACNAB, R. M. (1989). Export of an N-terminal fragment of Escherichia coli by a flagellum-specific pathway. Proceedings of the National Academy of Sciences of the United States of America 86, 4953-4957.

Lavallie, E. R. \& Stahl, M. L. (1989). Cloning of the flagellin gene from Bacillus subtilus and complementation studies of an in vitroderived deletion mutation. Journal of Bacteriology 171, 3085-2094.

Limberger, R. J., Slivienski, L. L., Yelton, D. B. \& Charon, N. W. (1992). Molecular genetic analysis of a class B periplasmatic flagellum gene of Treponema phagedenis. Journal of Bacteriology 174, 6404-6410.

Logan, S. M., TRUST, T. J. \& GuerRY, P. (1989). Evidence for posttranslational modification and gene duplication of Campylobacter flagellin. Journal of Bacteriology 171, 3031-3038.

MARTIN, J. H. \& SAVAGE, D. D. (1988). Cloning, nucleotide sequence and taxonomic implications of the flagellin gene of Roseburia cecicola. Journal of Bacteriology 170, 2612-2617.

Mitchison, M., Rood, J. I., FAINE, S. \& AdLER, B. (1991). Molecular analysis of a Leptospira borgpetersenii gene encoding an endoflagellar subunit protein. Journal of General Microbiology 137, 1529-1536.

Nauman, R. K., Holt, S. C. \& Cox, C. D. (1969). Purification, ultrastructure, and composition of axial filaments from Leptospira. Journal of Bacteriology 98, 264-280.

Norris, S. J., Charon, N. W., Cook, R. G., Fuentes, M. D. \& LIMBERGER, R. J. (1988). Antigenic relatedness and N-terminal sequence homology define two classes of periplasmic flagellar proteins of Treponema pallidum subsp. pallidum and Treponema phagedenis. Journal of Bacteriology 170, 4072-4082.

NuIJTEn, P. J. M., van Asten, F. J. A. M., GaAstra, W. \& van DER ZEISST, B. A. M. (1990). Structural and functional analysis of two Campylobacter jejuni flagellin genes. Journal of Biological Chemistry 265, 17798-17804.

Pallesen, L. \& Hindersson, P. (1989). Cloning and sequencing of a Treponema pallidum gene encoding a 31·3-kilodalton endoflagellar subunit (FlaB2). Infection and Immunity 57, 2166-2172.

PASTER, B. J. \& CANALE-PAROla, E. (1980). Involvement of periplasmic fibrils in motility of spirochetes. Journal of Bacteriology 141, 359-364.

Pearson, W. R. \& LiPMAN, D. J. (1988). Improved tools for biological sequence comparison. Proceedings of the National Academy of Sciences of the United States of America 85, 2444-2448.

SambroOK, J., Fritsch, E. F. \& Maniatis, T. (1989). Molecular Cloning, a Laboratory Manual. Cold Spring Harbor, NY: Cold Spring Harbor Laboratory.

Stanton, T. B., Jensen, N. S., Casey, T. A., Tordoff, L. A., DewhIRST, F. E. \& PASTER, B. J. (1991). Reclassification of Treponema hyodysenteriae and Treponema innocens in a new genus, Serpula gen. nov., as Serpula hyodysenteriae comb. nov. and Serpula innocens comb. nov. International Journal of Systematic Bacteriology 41, 50-58.

Taylor, D. J. \& Alexander, T. J. L. (1971). The production of dysentery in swine by feeding cultures containing a spirochaete. British Veterinary Journal 127, 58-61.

TOTTEN, P. A. \& LORY, S. (1990). Characterization of the type a flagellin gene from Pseudomonas aeruginosa PAK. Journal of Bacteriology 172, 7188-7199.

Wieland, F., Paul, G. \& Sumper, M. (1985). Halobacterial flagellins are sulfated glycoproteins. Journal of Biological Chemistry 260, 15180-15184.

Young, R. A. \& DAvis, R. W. (1983). Efficient isolation of genes by using antibody probes. Proceedings of the National Academy of Sciences of the United States of America 80, 1194-1198. 